\title{
Ingenieros militares en la Nueva Granada durante el siglo XVIII. Movilidad, proyectos y expediciones*
}

\author{
por \\ Manuel Gámez Casado ${ }^{1}$ \\ Universidad de Sevilla
}

El presente artículo tiene como objetivo analizar el grado de movilidad de los ingenieros militares entre las principales ciudades del litoral caribeño del virreinato de la Nueva Granada durante el siglo XVIII. A partir de los resultados obtenidos, se podrá valorar la trascendencia de los desplazamientos entre las regiones en función de las distintas misiones que los ingenieros debían afrontar. Asimismo, se comparará el caso neogranadino con el de otros territorios caribeños.

Palabras Clave: ingeniero; Caribe; movilidad; guerra; historia de América.

Cómo Citar este artículo / Citation: Gámez Casado, Manuel, "Ingenieros militares en la Nueva Granada durante el siglo XVIII. Movilidad, proyectos y expediciones", Revista de Indias, LXXIX/277 (Madrid, 2019): 765-796. https://doi.org/10.3989/revindias.2019.022.

\section{INTRODUCCIÓN}

Dentro de las distintas líneas de investigación desarrolladas por la historiografía contemporánea destaca el estudio de la ingeniería militar española en Época Moderna. Al respecto, son numerosas las publicaciones monográfi-

* El presente trabajo forma parte de los resultados obtenidos por el proyecto de investigación I+D "Ingenieros militares en el Caribe y el Golfo de México durante el siglo XVIII. Diálogo cultural, circulación trasnacional y conflictos globales", HAR2015-63805-P, financiado por el Ministerio de Economía y Competitividad del Gobierno de España.

1 mgamez@us.es, ORCID iD: https://orcid.org/0000-0002-5539-1104. 
cas que han centrado sus análisis en la producción de dicha disciplina en América, aunque en ocasiones únicamente se ocupen de documentar la historia de las fortificaciones o aspectos relativos al contexto institucional ${ }^{2}$. Ello no ha permitido valorar otras tareas realizadas por los ingenieros, quienes destacaron por una versatilidad muy superior a la de otros creadores. En este sentido, además de sus competencias técnicas, asumieron labores de representación diplomática, encabezaron numerosas expediciones para pacificar a las tribus locales y se preocuparon por reconocer el territorio ${ }^{3}$. Todo ello les permitió adquirir un conocimiento sobre el medio indiano plasmado en textos y descripciones, que resultaron muy útiles para la transferencia cultural producida de forma recíproca entre la Península Ibérica y América ${ }^{4}$.

Esta productiva actividad desarrollada por los ingenieros fue posible gracias a la movilidad experimentada, circunstancia que suplía la falta de otros profesionales que dirigiesen tareas edilicias. Igualmente, gracias a estos movimientos se encubrió la escasez de estos militares en varias plazas hispanas durante algunas décadas del siglo XVIII, pues tan vasto territorio requería de una cantidad inabarcable de efectivos. Por ello, era usual que se desplazasen a varios destinos durante el mismo año, al tener que resolver las necesidades de los distintos enclaves. En este sentido, no solo se ocupaban de la seguridad de las plazas, sino también de diseñar edificios civiles y religiosos, así como infraestructuras que mejorasen las comunicaciones 5 . Al emprender estas ocupaciones asumían un papel preponderante en el correcto funcionamiento de la defensa española, responsabilizándose de salvaguardar los dominios de Ultramar y de mediar entre el enemigo y la Corona, ejerciendo, en ocasiones, como representantes del poder virreinal ${ }^{6}$.

2 Cuantiosos son los estudios que han analizado los trabajos de los ingenieros militares españoles en América. De entre ellos, pueden verse los que se citan a continuación. Zapatero, 1978. Calderón Quijano, 1984. González Tascón, 1992. Gutiérrez, 2015. Mazorra Acosta, 2009: 37-46. Moncada, 2011: 79-101. Luengo Gutiérrez, 2013: 261-266. Cruz Freire y López Hernández, 2017.

3 Estas labores emprendidas por los ingenieros y complementarias al diseño de fortificaciones ya fueron destacadas por los siguientes autores. Guarda, 1966: 5-55. Oliveros de Castro, 1967: 79-111. Langebaek, 1989: 41-50. Moncada, 1994. Rodríguez Hernández, 2014: 59-78. Polo Acuña, 2001: 213-250. Laorden, 2008.

4 Véase AA.VV., 1983. Ejemplo de estas descripciones son los textos escritos por el ingeniero Miguel Constanzó durante su viaje por la Alta California. Al respecto, consúltese Moncada, 2012.

5 Véase Cámara y Revuelta, 2016 y Gámez Casado, 2018d.

6 Kuethe, 1970: 467-481. Para conocer más sobre el papel de los ingenieros en la política de guerra borbónica, véase Kuethe y Kenneth, 2014. 
Estas responsabilidades requerían de una distribución precisa de los ingenieros según los intereses territoriales de la Corona, teniendo cada uno de ellos una media de hasta cinco destinos a lo largo de sus carreras ${ }^{7}$. Como es lógico, dicha cifra disminuía en tiempos de paz y conforme éste envejecía o conseguía la autorización real para casarse, lo que encarecía los viajes de acuerdo a la norma reglada por el Real Cuerpo de trasladarse junto a sus familias ${ }^{8}$.

La heterogeneidad de los proyectos encabezados por los ingenieros militares alcanzó su máxima expresión en los desarrollados en la Nueva Granada durante el siglo XVIII. Bien sabido es como con la fundación de dicho virreinato en 1717, la Corona española pretendía solucionar la situación administrativa de las Audiencias de Panamá y Santa Fe. Asimismo, se acotaba un territorio formado por realidades tan numerosas como dispares, hallándose tanto algunos de los puertos más importantes de toda la América hispana, caso de Cartagena de Indias o Portobelo, como distintas tribus indígenas que, habitando en el Darién y en La Guajira, se escapaban del control político impuesto por otras instituciones 9 .

Del mismo modo, la ausencia de un sistema defensivo eficaz que protegiese Tierra Firme era consecuencia de una coyuntura castrense desastrosa, ya que los continuos ataques enemigos impedían asegurar poblaciones como Santa Marta o Maracaibo. Ello obligó a reorganizar la defensa marítima, para lo que se fundaron hasta tres comandancias militares al norte del nuevo virreinato con sedes en Caracas, ocupada de la custodia de la Capitanía General de Venezuela y cuyo dominio se extendía entre Maracaibo y el Orinoco, otra en Cartagena de Indias, con jurisdicción sobre Santa Marta y Ríohacha, y una tercera en Panamá, con potestad para la defensa del istmo ${ }^{10}$.

Representada esta división en el plano de la figura 1, se explicita la amplia distancia existente entre las distintas capitales, pues desde la desembocadura del río Chagres, preservada por el fuerte de San Lorenzo, hasta Cumaná, en el extremo oriental del virreinato, existen cientos de kilómetros de litoral a defender. Esta lejanía, unida a la multitud de ríos, fondeaderos y bahías que

7 Galland Seguela, 2005: 223.

8 Capel, Sánchez y Moncada, 1988: 294 y ss.

9 Entre éstos, destacan las labores de inspección ejercidas por los guardacostas reales en el entorno del Darién, impidiendo el contrabando de productos ilegales entre nativos e ingleses. Un ejemplo de estas expediciones ha sido estudiado por Gámez Casado, 2018a: 211-236.

10 Navarro García, 1975: 95-97. Estas divisiones se integraban en las Audiencias fundadas para la mejora de la organización del virreinato. Además de las bien conocidas Audiencias de Santa Fe y Panamá, existía una tercera con sede en Quito. Herrera Ángel, 2001: 76-104. 
jalonan dicha costa, dificultaba el amparo de los puertos, necesitando de una estructura militar que contrarrestase los apuros geográficos existentes.

Asimismo, esta realidad territorial convirtió a la costa de la Nueva Granada en el epicentro del contrabando caribeño, lo que perjudicaba tanto a la economía española, como a la hegemonía de la Corona en las regiones controladas por los líderes tribales ${ }^{11}$. Precisamente, el presente análisis se centrará en el caso de las principales capitales del litoral neogranadino, señaladas en el mencionado plano y consideradas como puntos claves del gobierno español en el Nuevo Mundo, pues algunas de ellas llegaron a ser calificadas como las verdaderas llaves de las Indias.

Figura 1. Mapa general de las comandancias de Panamá, Cartagena DE INDIAS Y CARACAS Y SUS PRINCIPALES PROVINCIAS. VIRREINATO DE LA Nueva Granada. Siglo XVIII

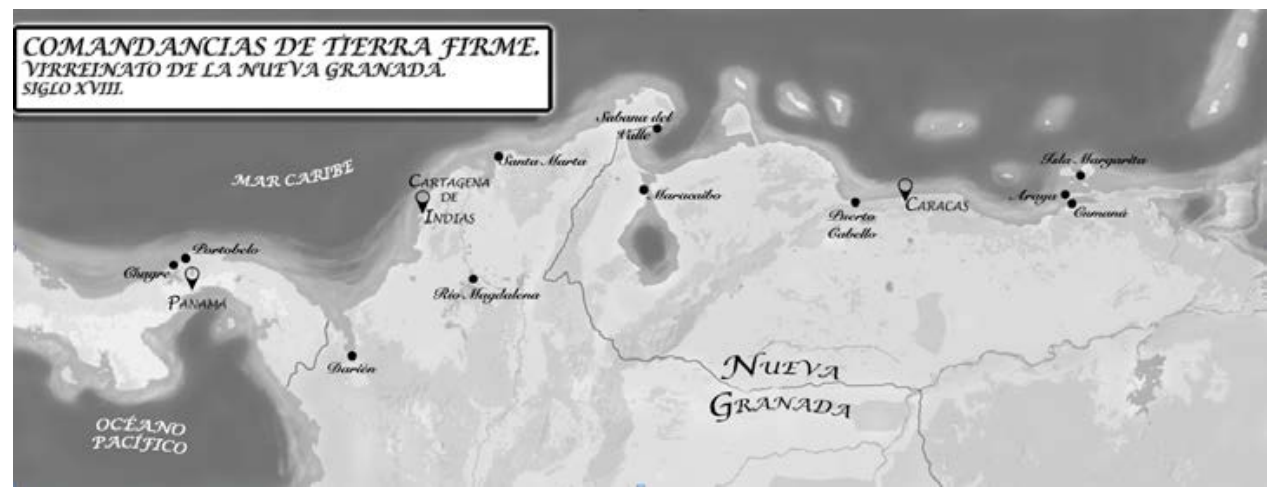

Fuente: elaboración propia.

Dentro de este contexto, los ingenieros militares fueron considerados como parte de la administración neogranadina, encargándose de las bien conocidas labores arquitectónicas y de las tareas de organización y gestión del terreno a controlar. Estas obligaciones exigían algunos desplazamientos entre las distintas plazas, advirtiéndose una importante presencia de éstos en varios puntos del Caribe sur según conviniese. Ello repercutió en un aumento considerable de efectivos durante el siglo XVIII, alcanzando la mayor concentración de

11 Ramos, 1990: 357-372. Asimismo, al contrabando de mercancías entre ingleses y nativos en aguas caribeñas se refieren varios autores. Gómez Molleda, 1950: 336-369. Robles y Tau, 1980. Ojeda Pérez, 2007: 93-113. 
ingenieros y desarrollando numerosos proyectos que reforzaron o crearon nuevos elementos defensivos en poblaciones como Cartagena de Indias o Puerto Cabello. Para ello, dichos profesionales generaron una amplia serie de propuestas, cuyos planos se conservan en distintos archivos españoles y que dan testimonio de sus intereses, aspiraciones y afanes. De este modo, el estudio de dicha planimetría permite conocer los objetivos que influyeron en la presencia de ingenieros en las principales capitales del Nuevo Reino de Granada según cada década del siglo ${ }^{12}$.

Así, es indispensable establecer una conexión multidisciplinar que aúne el conocimiento de la historia virreinal neogranadina con otras fuentes. La realización de una base de datos que registre cada uno de los planos trazados por los ingenieros en las distintas ciudades, ya permitió extraer llamativas conclusiones con respecto a la isla de $\mathrm{Cuba}^{13}$. Ahora se aplica esta metodología en relación a los que trabajaron en la Nueva Granada, anotando los mapas, planos y proyectos conservados en los archivos estatales para generar una serie de esquemas que aporten información acerca de la movilidad de dichos militares. Además, estos datos se completarán con la consulta de fuentes primarias, destacando los expedientes personales de los más distinguidos ingenieros en los que se detallan sus ascensos y traslados. Igualmente, la lectura de otras publicaciones permitirá ahondar en el conocimiento sobre el tema que se desarrolla en estas líneas, pues existe una interesante bibliografía especializada en registrar los datos biográficos, resultando de gran utilidad para el estudio de la movilidad ${ }^{14}$.

Todo ello facilitará conocer los desplazamientos no solo entre las principales capitales de los actuales países de Panamá, Colombia y Venezuela, sino también entre otras regiones de menor trascendencia edilicia, pero de relevante interés social, como son el Darién o La Guajira. Además, la movilidad acredita la labor de estos profesionales en Tierra Firme, demostrando la preponderancia de unos puertos sobre otros en función de su localización, actividad mercantil y repercusión política. Igualmente, se relacionarán los traslados de los ingenieros con las distintas problemáticas a las que tuvieron que hacer frente, valorando sus producciones civiles, diplomáticas y cartográficas, marginadas por la historiografía tradicional que solo ha atendido al diseño de fortificaciones.

12 En el presente análisis se estudiará la presencia de ingenieros militares en el Chagres, Portobelo, Darién, Cartagena de Indias, Santa Marta, La Guajira, Maracaibo, Puerto Cabello, Araya, Guaira y Cumaná.

13 Luengo Gutiérrez, 2014: 36-47.

14 De entre las publicaciones que han recogido los traslados de los ingenieros españoles, véase AA.VV., 1983. 
2. Entre el Chagres y Cumaná. Ingenieros militares en el Sur del CARIBE.

Los ingenieros desarrollaron una amplia producción arquitectónica en el litoral sur del Caribe desde las primeras décadas de la conquista americana, destacando la presencia de Juan Bautista Antonelli en diversas ciudades a fines del Quinientos ${ }^{15}$. A pesar de ello, durante los siglos XVI y XVII fue escaso el número de los que trabajaron en Tierra Firme, pues al pertenecer al virreinato del Perú, la defensa se relegaba a los puertos de mayor importancia comercial, especialmente a los de Cartagena de Indias y Portobelo ${ }^{16}$. Pero esta realidad varió a lo largo del Setecientos, multiplicándose la presencia de ingenieros al afrontarse otros cometidos de carácter social, cultural y arquitectónico.

De este modo, atendiendo al diagrama de la figura 2, se observa como durante las primeras décadas del siglo XVIII continuó siendo limitado el número de estos militares en las tres comandancias neogranadinas citadas, a pesar de haberse afrontado la reconstrucción de varios puertos tras los ataques enemigos producidos a fines de la centuria anterior ${ }^{17}$. Del mismo modo, este dato testimonia como eran pocos los ingenieros que aceptaban el destino americano, rechazando esta propuesta los de mejor formación, quienes preferían trasladarse a otros puntos de los territorios hispanos. Este hecho denota que la estructuración desde 1711 del Real Cuerpo de Ingenieros no generó una mayor disponibilidad con respecto al pase a Ultramar, manteniéndose un elevado número de militares no formados técnicamente al frente de las defensas de varias ciudades caribeñas ${ }^{18}$.

15 Véase Angulo Íñiguez, 1952. Más reciente es el estudio realizado por De la Torre Echávarri, 2014: 113-135.

16 De todos los ingenieros que trabajaron en la Nueva Granada durante el siglo XVII, destacan los considerados por la historiografía como discípulos de Antonelli, entre los que se encontraban su hijo Juan Bautista Antonelli el Mozo, Cristóbal de Roda y Juan de Somovilla, ingeniero ayudante que asumió la dirección de las obras de Cartagena de Indias mientras sus superiores se encargaban de la defensa de Araya y Cumaná. Marco Dorta, 1988: 180-188.

17 Me refiero al ataque del barón de Pointis sobre Cartagena de Indias efectuado en 1697, que destruyó el sector norte de la muralla y parte del sistema defensivo abaluartado, lo que requeriría de una intervención inmediata que asegurase la protección de la ciudad. Porras Troconis, 1942: 81-90. Borrero Londoño, 2009: 368- 390. Gámez Casado, 2017: 179-184.

18 Capel, Sánchez y Moncada, 1988: 317-318. 
Figura 2. Número de ingenieros militares en la Nueva Granada DURANTE EL SIGLO XVIII

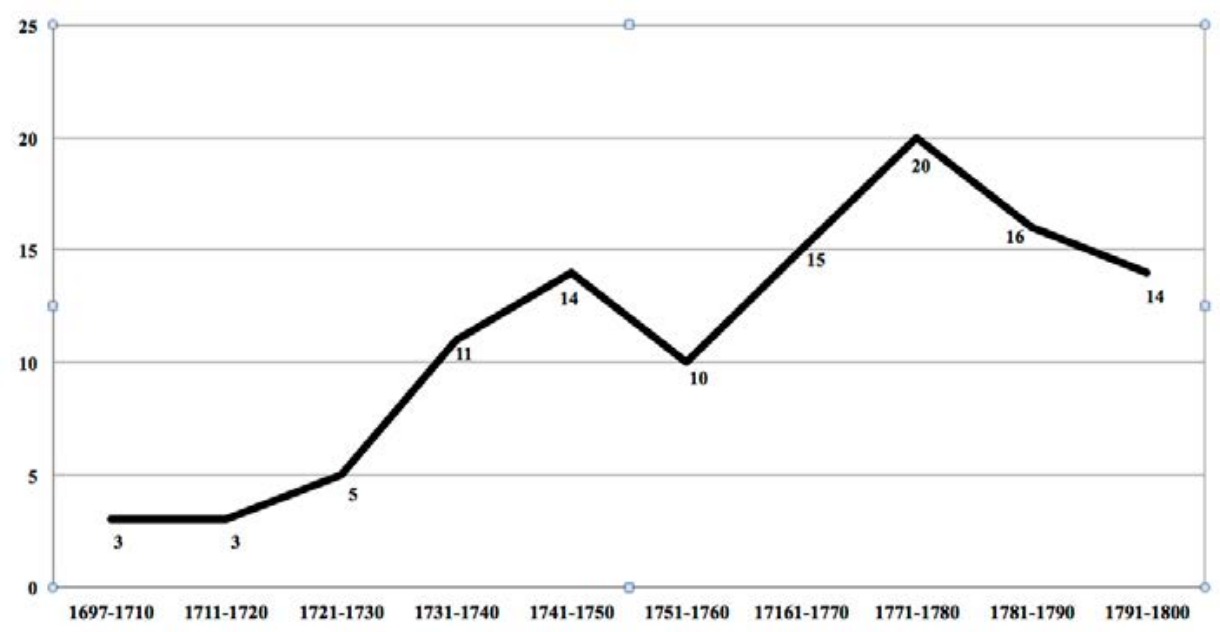

Fuente: elaboración propia.

Esta situación contrasta con la producida a partir de 1731, cuando el número de efectivos superó la decena. Ello generó importantes concentraciones de ingenieros en ciudades como Puerto Cabello, en la que se afrontaba la construcción del fuerte de San Felipe bajo la dirección de Juan de Gayangos Lascari y Juan Amador Courten, quien compaginó estas tareas con las asumidas en el golfo de Cumaná ${ }^{19}$. No obstante, durante los años sucesivos al ataque del vicealmirante Edward Vernon, las posibilidades de trasladarse entre las distintas plazas del litoral meridional se redujeron, pues los ingenieros fueron obligados a permanecer en sus destinos con el fin de reconstruir las defensas ${ }^{20}$. Por esta razón, dentro del contexto que se atiende, parece que únicamente Antonio de Arévalo se desplazó entre las ciudades estudiadas, al estar documentada su presencia en Cartagena de Indias y Santa Marta durante la década de 1740, convirtiéndose en un caso aislado de entre cuantos se han estudiado ${ }^{21}$.

19 Zapatero, 1988: 53-115. Asimismo, consúltese González, 1979: 127-137.

20 Serrano Álvarez, 2006: 359-383. Para saber más sobre los ataques del vicealmirante Edward Vernon a la Nueva Granada, consúltense las siguientes obras. Justiniano Carranza, 1874. Lozano, 1993: 39-47. Porto de González, 1996: 679-694. López Guzmán y Cabrera Cruz, 2017: 49-75.

21 Zapatero, 1981: 446. 
Este bloqueo disminuyó durante los años siguientes al producirse un descenso cuantitativo de ingenieros, producto de la falta de medios económicos de la Corona ante la multitud de proyectos que afrontaba tras las guerras de mediados de siglo. No obstante, en torno a 1765 la presencia de estos militares se triplicó, iniciándose la época dorada de la ingeniería militar neogranadina. La necesidad de rehabilitar las fortificaciones atacadas por los ingleses y de modernizar los sistemas defensivos de las principales capitales concentró en la zona hasta quince efectivos. Asimismo, a través de la Ordenanza de 1768 se incrementó el apoyo recibido para pasar a América, al acordarse un incentivo económico por movilidad y un ascenso a la categoría superior a cambio de permanecer en el destino durante cinco años ${ }^{22}$. Es posible que estas razones fuesen una motivación para algunos en la decisión de pasar a las Indias, aunque no debe pensarse que condicionasen sus traslados.

Aparte de estas circunstancias, la década de 1770 debe considerarse como la de mayor productividad edilicia, al emprenderse la construcción de varias fortificaciones en la totalidad de los puertos neogranadinos por una veintena de ingenieros. Este incremento se mantuvo con leves modificaciones hasta el final de la centuria, convirtiendo al último cuarto del siglo XVIII en el de mayor interés para el estudio de la ingeniería militar en el Nuevo Reino.

Estos datos nos permiten comparar la amplia presencia de ingenieros españoles en la Nueva Granada con respecto a otros ámbitos indianos, caso del virreinato de Nueva España ${ }^{23}$ (figura 3). De este modo, el parejo número de éstos localizados en ambos territorios durante la primera mitad del siglo XVIII, contrasta con las diferencias existentes a partir de 1750. Desde ese año $\mathrm{y}$ durante la década siguiente, fueron quince los que trabajaron en el virreinato más septentrional, mientras que en la zona sur del Caribe tan solo llegaron a diez. Así, resulta evidente que las consecuencias de la Guerra del Asiento (1739-1748) generaron palpables diferencias en la constitución de los sistemas defensivos de estos territorios ${ }^{24}$.

Ciertamente, en ambos virreinatos existió un número parejo de capitales primordiales en la red comercial española establecida en América, pues si Cartagena de Indias y Portobelo destacaban en el ámbito meridional por su estratégica localización, Veracruz y La Habana alcanzaron el mismo rango en

22 Capel, Sánchez y Moncada, 1988: 326. Igualmente, véase Morales, 2014: 71.

23 Para el presente estudio, se ha computado la presencia de ingenieros militares durante el siglo XVIII en las siguientes ciudades novohispanas: Veracruz, Perote, Campeche, Laguna de Términos, Bacalar, Mérida, Sisal, La Habana, Santiago de Cuba, Matanzas, Jagua, Santo Domingo y Omoa.

24 Moncada, 1992: 11-47. 
el norte, al erigirse como los puertos principales para la circulación de mercancías hacia la Península Ibérica. De este modo, fallidos los ataques ingleses a las mencionadas ciudades neogranadinas, los esfuerzos de las tropas lideradas por Edward Vernon y Charles Knowles se centraron en conquistar Cuba, destruyendo sus fortificaciones y murallas. Ante esta circunstancia, la Corona destinó a la isla cubana el $50 \%$ de los quince ingenieros presentes en Nueva España durante la década de 1750, designándoles la reconstrucción de las defensas y la protección de los puertos comerciales hispanos.

Sin embargo, la diferencia en el número de ingenieros militares distribuidos en los dos virreinatos citados aumentó a partir de la Guerra de los Siete Años (1756-1763), conflicto que desembocó en la toma de La Habana por los británicos ${ }^{25}$. Por esta razón, existe una ingente documentación epistolar escrita por los gobernadores solicitando la presencia de un mayor número de ingenieros en sus plazas e inmediaciones. Así, durante el gobierno del virrey Bucarelli se alcanzó hasta cuarenta y tres efectivos trabajando en las principales ciudades novohispanas, de los cuales el 70\% se destinó a México. Este número instituye al virreinato de Nueva España como la Dirección de Ingenieros más importante de América a lo largo del siglo XVIII. Asimismo, es interesante destacar como dicha cifra dobla a la contabilizada en la Nueva Granada, ya que en la década de 1770, esto es, durante el gobierno del virrey Manuel Guirior, apenas se alcanzaron los veinte ingenieros.

Más allá de comparaciones entre ambas realidades, lo cierto es que durante esos años se congregaron en el Caribe no solo el más alto número de ingenieros, sino también los más capacitados, posibilitando la finalización de fortificaciones tan emblemáticas como la cartagenera de San Felipe de Barajas, la veracruzana de San Juan de Ulúa o el castillo del Morro en La Habana. A partir de aquí, durante las dos últimas décadas del Setecientos descendió en paralelo el número de ingenieros en los dos reinos, siendo en todo momento superior la cuantía de éstos en Nueva España.

Los datos presentados denotan el interés de la Corona por asegurar las principales plazas caribeñas, solventando con ello la continua amenaza inglesa. Para conseguir tal propósito en Nueva España, distintos ingenieros se desplazaron entre las regiones, pues más allá de los reconocimientos efectuados por Agustín Crame, otros como Luis Díez Navarro, Félix Prósperi o Joaquín Peramas se movieron entre las capitales para dirigir las obras de fortificaciones ${ }^{26}$. Este dato confirma la pareja movilidad de estos ingenieros en los dos virrei-

${ }^{25}$ La repercusión que dicho enfrentamiento causó en términos globales ya ha sido analizada por Luengo Gutiérrez, 2017a: 4-27.

26 Calderón Quijano, 1950: 1-72. 
natos comparados, siendo similar a la realidad neogranadina. Allí, algunos como Antonio de Arévalo, José Antonio Brist o Juan Antonio Perelló se caracterizaron por sus cambios de destino, encabezando diferentes planes que requerían de continuos desplazamientos por la costa sur del Caribe.

FiguRA 3. COMPARACIÓN DEL NÚMERO DE INGENIEROS MILITARES ENTRE LOS VIRreinatos de la Nueva Granada y de Nueva España duRANTE el Siglo XVIII

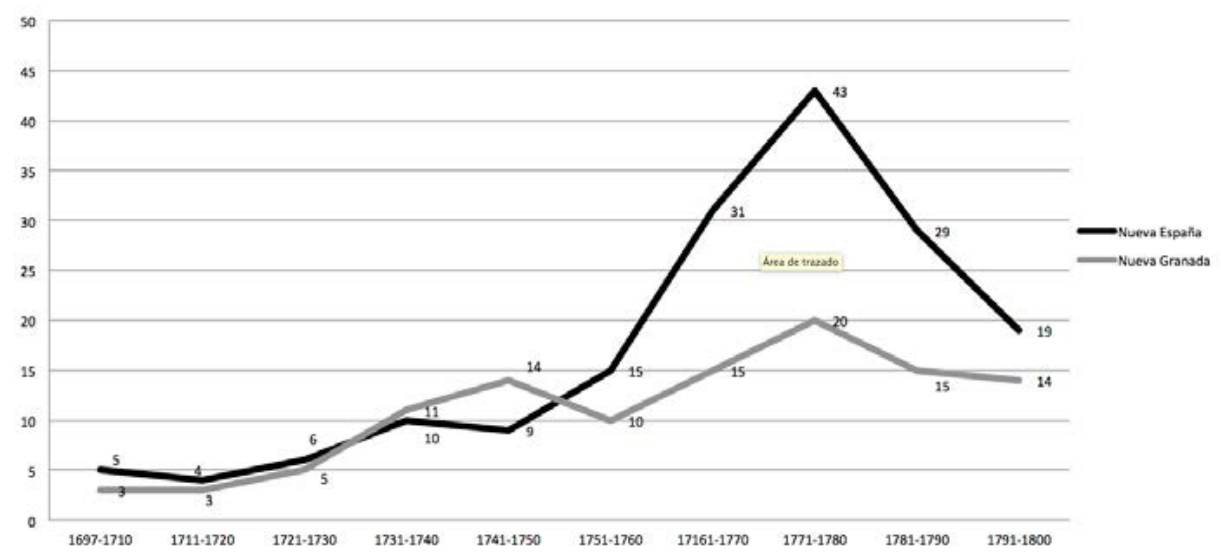

Fuente: elaboración propia.

3. LA PRESENCIA DE LOS INGENIEROS MILITARES EN LAS PRINCIPALES CIUDADES DE LA NuEVA GRANADA (1697-1741)

Lo analizado evidencia que los ataques del vicealmirante inglés Edward Vernon a Portobelo y Cartagena de Indias, produjeron un cambio en la mentalidad del gobierno virreinal, asumiéndose la necesidad de establecer un adecuado sistema defensivo en toda la costa meridional del Caribe. De ello se podría deducir que, en consecuencia, la movilidad de los ingenieros entre las distintas capitales fue mayor, pues había que defender un mayor número de plazas. Sin embargo, la mejor formación académica de éstos, unido a la necesidad de finalizar una amplia nómina de proyectos en ciudades estratégicas, generaron pocos cambios de destino a lo largo de las primeras décadas del Setecientos. Los esfuerzos se centraron en proteger plazas de trascendencia comercial como Puerto Cabello, donde los almacenes de la Real Compañía Guipuzcoana requerían del más actualizado sistema de fortificación. En cambio, otras como Maracaibo tuvieron una escasa activi- 
dad arquitectónica, luego tras los trabajos de reparación del castillo de San Carlos a fines del siglo XVII, la presencia de ingenieros fue nula, ocupándose de la defensa de la zona los castellanos o militares de otros Cuerpos hasta el mandato interino de Altube ${ }^{27}$.

Por otro lado, en la gráfica de la figura 4 se ofrece una comparación de la producción de los principales ingenieros destinados en las ciudades de Tierra Firme hasta el citado ataque inglés. En ella se observa cómo únicamente Juan de Herrera y Sotomayor y su discípulo José de Figueroa destacaron por su movilidad, justificada al ser los responsables de los proyectos de mayor importancia estratégica. Por ello, se hallaron en pocos años en el Darién, Cartagena de Indias, Panamá, Portobelo y Santa Marta, atendiendo a misiones diplomáticas y a tareas constructivas. Tanto es así que la historiografía, sin fundamento alguno, ha querido ver en la relevante productividad de Herrera la creación de un estilo abaluartado propio, genuinamente americano y consecuente con la fundación de una Escuela de Fortificación Hispanoamericana ${ }^{28}$.

Figura 4. Producción de LoS PRINCIPALES INGENIERoS MiLITAReS EN LAS PROVINCIAS DE La NueVa GRANADA. 1697-1741



Fuente: elaboración propia.

27 López Rivero, 1965: 94.

28 Zapatero, 1966: 261-275. 
Esta capacidad de traslado contrasta con la de otros ingenieros coetáneos, cuyos movimientos por la costa eran menores, caso de José Franco, Alberto Mienson o Luis Segretier, quienes, bajo la dirección de Herrera, se encargaron únicamente de las obras de Cartagena. Es el mismo caso de Nicolás Rodríguez, al que se documenta por aquellos años trabajando en las fortificaciones panameñas del Chagres, punto que requería de una defensa superior al controlar la entrada del río homónimo. Allí, la dificultosa empresa de dirigir las reformas del fuerte de San Lorenzo le obligó a viajar desde las obras del castillo Real Felipe del Callao, junto a Lima, hasta Panamá en $1730^{29}$. Ello denota una mayor amplitud geográfica en la movilidad de Rodríguez, convirtiéndolo junto a Herrera y Sotomayor, quien había trabajado en Valparaiso, en dos de los escasos ingenieros que trabajaron en virreinatos diferentes, circunstancia excepcional entre los tratados hasta la fecha.

Muy diferente fue el caso de Pablo Díaz Fajardo, quien permaneció en Cumaná durante estas primeras décadas al frente de los proyectos del castillo de San Antonio y Santa María de la Cabeza hasta que finalmente fue destinado a Puerto España ${ }^{30}$. También en Cumaná trabajó Juan Amador Courten hasta que en 1733 fue enviado a Puerto Cabello, donde desarrolló lo principal de su producción. Idéntico caso son los de Juan de Gayangos Lascari y sus subalternos Ruíz de Olano y Jordán, quienes desde Puerto Cabello fueron trasladados al muelle caraqueño de La Guaira aprovechando la cercanía de ambas ciudades, lo que incentivaba un intercambio según las necesidades de cada plaza ${ }^{31}$. No obstante, estos últimos no solo carecen de la repercusión edilicia de ingenieros como Herrera, sino también de la movilidad que sus sucesores presentarán en las décadas siguientes.

De este modo, durante el periodo estudiado solo un $15,3 \%$ de los ingenieros activos en la Nueva Granada recorrieron más de $1000 \mathrm{~km}$, entendiendo ésta como una distancia suficiente para trabajar entre dos ciudades alejadas ${ }^{32}$. Por otro lado, el $46,1 \%$ transitó menos de dicha distancia, por lo que a pesar de haberse desplazado entre ciudades, éstas estaban cerca ${ }^{33}$. Finalmente, el $38,4 \%$ no se movieron de la ciudad a la que fueron destinados, demostrándo-

29 Zapatero, 1985a: 155.

30 Luengo Gutiérrez, 2017b: 215-222.

31 Calderón Quijano, 1996: 359 y ss. Gasparini, 1979: 11-98.

32 Éstos son Juan de Herrera y Sotomayor y José de Figueroa.

33 A este grupo pertenecen Juan de Gayangos Lascari, Nicolás Rodríguez, Pablo Díaz Fajardo, Juan Amador Courten, Antonio de Jordán y Pedro Ruiz Olano. 
se cómo la movilidad en estos años fue escasa, pues son casos excepcionales los que trabajaron en varias plazas alejadas ${ }^{34}$.

\section{LA PRESENCIA DE LOS INGENIEROS MILITARES EN LAS PRINCIPALES CIUDADES DE LA Nueva Granada (1742-1800)}

Como se ha dicho, los devastadores ataques del vicealmirante inglés Edward Vernon destruyeron un alto porcentaje de las principales fortificaciones neogranadinas ${ }^{35}$. Consecuencia de ello fue el incremento del número de ingenieros, al centrarse los esfuerzos de la Corona en trazar una estrategia de amparo que frenase la continua amenaza británica. Para conseguirlo, se necesitaba no solo una cantidad suficiente de efectivos, sino también que estuviesen debidamente formados. Estas condiciones convirtieron a la segunda mitad del siglo XVIII en la etapa más fecunda, pues la cantidad de proyectos desarrollados terminaron de definir los sistemas defensivos de las principales ciudades. Gracias a la llegada de nuevos especialistas se culminaron edificios que eran resultado de reflexiones y planteamientos complejos, alcanzándose un esplendor arquitectónico que hará de fortificaciones como la cartagenera de San Felipe de Barajas un símbolo de la presencia española en América.

A través de estos mecanismo se intentaba frenar el progresivo dominio de Inglaterra, pues, como ya se ha apuntado, vencieron en la Guerra de los Siete Años, conquistaron La Habana en 1762 y consiguieron la aprobación dos años después del conocido como Acta del Azúcar, lo que les otorgaba una creciente presencia comercial en el Caribe ${ }^{36}$. Esta circunstancia obligaba a la Corona española a reforzar los puertos del sur caribeño, al partir desde allí algunas de las principales rutas mercantiles ${ }^{37}$. Asimismo, se optó por incrementar el número de guardacostas reales y por imponer medidas fiscales más severas que evitasen el aumento del contrabando, lo que repercutía en importantes pérdidas para la economía hispana ${ }^{38}$.

En este contexto, de entre los más destacados ingenieros militares que trabajaron en la segunda mitad del siglo XVIII, Agustín Crame se distinguió

\footnotetext{
34 Este fue el caso de Alberto Mienson, José Franco, Luis Segretier, Vicente Ignacio González y Carlos Briones.

35 Caso similar ocurrió en otras áreas del Caribe, caso de la isla de Cuba. Véase López Hernández, 2019: 117-207.

36 Brown, 2015: 133.

37 Pocock, 2002.

38 Kuethe y Kenneth, 2014: 244-331.
} 
por sus traslados, siendo el único de cuantos se analizan que estuvo hasta en ocho plazas distintas a lo largo del litoral neogranadino (ver figura 5). A todas ellas arribó en calidad de Visitador General de las Fortificaciones, cuyo cometido era examinar el estado de los edificios defensivos, los almacenes y la artillería de las capitales, convirtiéndose en un caso excepcional en el periodo tratado ${ }^{39}$. En cumplimiento de esta misión, Crame partió en 1777 desde Cumaná, alcanzando el Chagres dos años después, tras haber pasado por Puerto Cabello, Maracaibo, Santa Marta o Cartagena de Indias. Tan alto número de desplazamientos era consecuencia de su cargo, pues muy diferente fue la movilidad del resto de sus compañeros.

Figura 5. Producción de LOS PRINCIPALES INGENIERoS MiLITARES EN LAS PROVINCIAS DE LA NuEVa GRANADA. 1742-1800

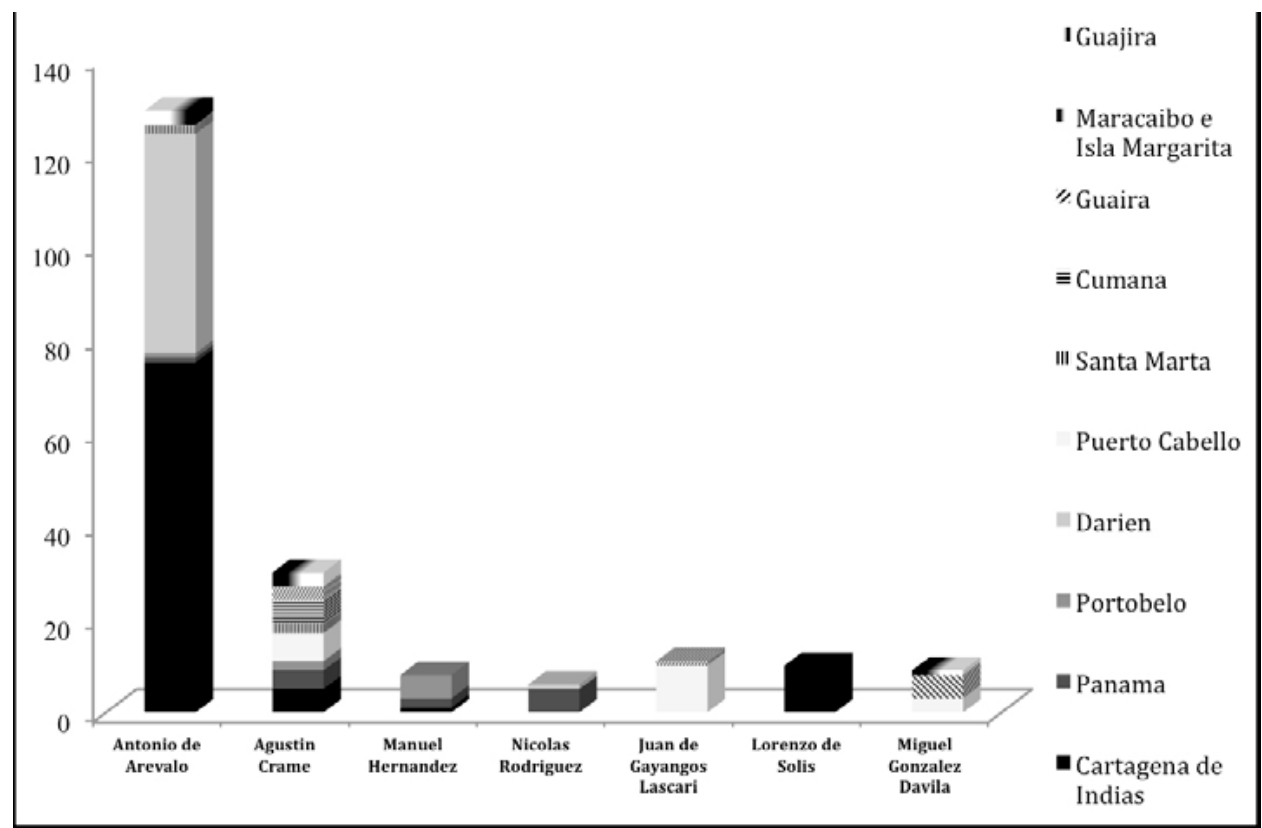

Fuente: elaboración propia.

En este sentido, se distingue un grupo de ingenieros ampliamente formados, cuyas motivaciones de movilidad a lo largo del virreinato eran diferentes a las

39 Arcos Martínez, 2016: 1-38. 
del propio Crame. De ellos no solo dependía la proyección de las fortificaciones de Cartagena de Indias, Portobelo o Santa Marta, sino también el reconocimiento de las belicosas tribus del Darién y de La Guajira, considerados hasta ahora destinos secundarios. Éste fue el caso de José Díaz de Pedregal, Juan Jiménez Donoso o Antonio de Arévalo, exponentes de la estrategia diplomática de pacificación indígena alentada por la Corona en estos años. Precisamente Arévalo destacó por su amplia producción planimétrica, producto de los numerosos proyectos que asumió durante la dirección de las obras de defensa cartagenera.

Distinto caso fue el de otros ingenieros enviados a una capital de gobernación para hacerse cargo de las provincias dependientes, caso de Miguel González Dávila, destinado a las plazas subordinadas de la comandancia de Caracas, o Manuel Hernández y Francisco de Navas, encargados de la defensa del territorio panameño. Asimismo, es interesante resaltar otros ejemplos que destacaron por la lejanía de sus destinos, pues viajaron entre ciudades pertenecientes a virreinatos diferentes. Éste fue el caso de Lorenzo de Solís, quien partió del puerto cartagenero rumbo a Veracruz, de Simón Desnaux, trasladándose desde Cartagena de Indias a Guatemala, o de Ignacio Sala, quien tras trabajar en Tierra Firme regresó en 1754 a Cádiz ${ }^{40}$. Por último, destaca el caso excepcional de Antonio de Narváez, criollo que accedió al Real Cuerpo tras demostrar una experiencia previa. Ello le permitió desplazarse hasta la Península Ibérica para desarrollar nuevos proyectos y completar su formación, regresando a fines del siglo XVIII para ocuparse de las obras de Santa Marta y Panamá ${ }^{41}$.

Así, durante este periodo, el $15,7 \%$ de los ingenieros activos en la Nueva Granada recorrieron más de $1000 \mathrm{~km}^{42}$. El 17,5\% corresponde a aquellos que viajaron menos distancia, ya que las ciudades a las que les destinaron se encontraban relativamente cerca ${ }^{43}$. Por último, el $66,6 \%$ no se movió de la ciudad a la que fueron enviados, denotando cómo la movilidad en estos años continuaba siendo escasa. Ello demuestra que los casos de Crame o Arévalo son excepciones dentro de un contexto de estatismo con respecto a los movimientos de los ingenieros a lo largo del litoral caribeño de la Nueva Granada ${ }^{44}$.

40 Cruz Freire, 2013: 469-481.

41 Gámez Casado, 2018b: 237-246.

42 Éstos son Antonio de Arévalo, Manuel Hernández, Antonio de Narváez, Agustín Crame, José Antonio Brist, Juan Jiménez Donoso, Francisco Navas, Miguel González Dávila y José Díaz Pedregal.

43 A este grupo pertenecen Ignacio Sala, Nicolás Rodríguez, Juan de Gayangos Lascari, Juan de Casamayor, Juan Antonio Perelló, Bartolomé Amphoux, Miguel Marmión, Conde de Roncalli, Manuel de Anguiano y Fermín de Rueda.

44 Este fue el caso de Simón Desnaux, Juan Bautista Mac-Evan, Luís Antonio Pedrosa, José Solano, Luis Lazara, Manuel Pinto de Acosta, Luís Segretier, Lorenzo de Solís, Francis- 
5. ¿Cuestión de Rango? Movilidad de los ingenieros Según Sus GRados

Con la fundación del Real Cuerpo en 1711 se constituyó una escala facultativa que aunaba por un lado la tradición castrense española, con las nuevas ideas francesas asumidas tras la proclamación del rey Felipe V. Original en la graduación hispana fue el establecimiento en paralelo del escalafón de ingeniería e infantería, lo que facilitaba a la milicia ascender por una u otra vía ${ }^{45}$. Los distintos niveles fueron constituidos en el mencionado año a partir de las ideas sugeridas por Jorge Próspero Verboom, trasladándose de inmediato a las posesiones de Ultramar bajo la responsabilidad del Ingeniero General46. De este modo, en las líneas que siguen se analizará la movilidad de estos militares en la Nueva Granada en función del escalafón citado, comprobándose si la jerarquía impuesta por el Cuerpo influía en los desplazamientos. Para ello, en la gráfica de la figura 6, se ha representado el número de traslados en función de los grados existentes durante la mayor parte del siglo XVIII, posibilitando su comparación y precisando las diferencias entre las categorías.

Era propio de cada clase tener una serie de tareas predefinidas que los militares debían asumir con total garantía. De este modo, lo primero que demuestra la imagen es que los distintos grados se movían de forma pareja en función de las necesidades de cada plaza, pues las líneas que marcan los desplazamientos coinciden en muchas ocasiones. No obstante, la representación denota como los ingenieros extraordinarios fueron los más activos, aunque también eran los más numerosos. En este sentido, los graduados en este grupo alcanzaron una cota de trece traslados durante la primera mitad del siglo, evidenciando una exigencia mayor ante la falta de especialistas en la dirección de las obras neogranadinas. Pero este dato aumentó durante la década de 1770, superando la quincena de destinos y asumiendo un papel preponderante en la reconstrucción de las fortificaciones neogranadinas tras los ataques de mediados de la centuria.

co Requena, Mauricio de Bolívar, Antonio Marchante, José Parreño, José Joaquín de Pineda, Francisco Jacot, Roque Iglesias, Carlos de Arias, Vicente Talledo, Juan Cayetano Chacón, Juan Cearra Arévalo, Francisco Antonio del Mazo, Pedro Carbonell, Antonio de la Torre, Domingo Armayo, José Antonio Espelius, Esteban Aymerich, José Aparici, Javier Carol, Antonio Marchante, Andrés González Dávila, Alejandro Sánchez Taramas, Lorenzo Córdova, Carlos Superviela, Carlos Souvillard, Ramón de Anguiano, Domingo Esquiaqui, Ramón Ignacio Yoldi, José Antonio de Pozo y Casimiro Isava Oliver.

45 Muñoz Corbalán, 2015: 11-34.

46 Capel, Sánchez y Moncada, 1988: 256-257. 
Es cierto que hasta 1740 fue considerado el nivel más bajo del Cuerpo, aunque sus integrantes se encargaban de delinear los mapas y planos utilizados en las obras, siendo una tarea básica que requería nociones de geometría, dibujo y matemáticas. Por esta razón eran solicitados en distintas plazas de forma continua, destacando el caso de José de Figueroa, presente en hasta seis ciudades durante su pertenencia a este grado, o de Francisco de Navas, desplazado hasta en tres ocasiones ${ }^{47}$.

Figura 6. Movilidad de los ingenieros militares en la Nueva Granada DURANTE EL SIGLO XVIII EN FUNCIÓN DE LOS PRINCIPALES RANGOS ESTABLECIDOS EN LA eSCALA faCUltativa DEL ReAl CUERPO

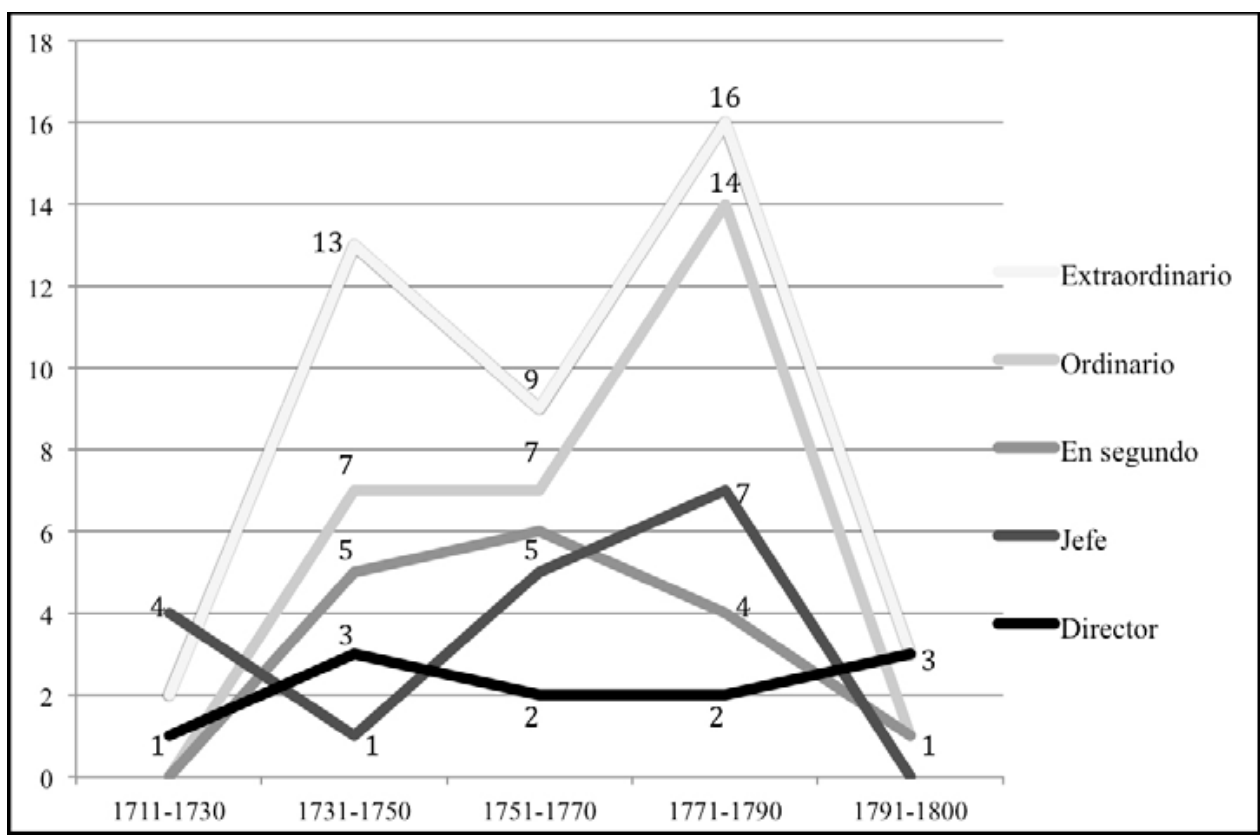

Fuente: elaboración propia.

Parejo en el número de movimientos se hallaban los ingenieros ordinarios, cuya estadística es similar a los situados en el rango inferior. Así, da la im-

47 Hoja de servicio de Francisco de Navas, Madrid, 6 de mayo de 1777, Fdo. Silvestre Abarca, Archivo General de Simancas, Simancas, Valladolid (en adelante AGS), Secretaría de Guerra, Indiferente, leg. 3793, c. 2, fol. 54. 
presión de que los extraordinarios trabajaban conjuntamente con éstos, pues son varios los ejemplos coincidentes en las principales ciudades, llamando la atención la movilidad de Juan Ximénez Donoso, presente en tres provincias distintas durante su estancia en este grado ${ }^{48}$.

Un escalafón superior lo formaban los ingenieros en segundo, cuya presencia en Tierra Firme destaca a mediados de siglo. Considerados una autoridad dentro del Cuerpo, la incorporación de estos militares en las plazas asediadas por los británicos facilitó la inmediata recuperación de la milicia, sobresaliendo la presencia del joven Manuel Hernández en Cartagena de Indias o del aún inexperto Conde de Roncalli en Puerto Cabello ${ }^{49}$.

Si comparamos los datos anteriores con los correspondientes al grado de ingeniero en jefe, parece que la década de 1770 vuelve a ser la de mayor actividad, aunque tanto el número de desplazamientos, como el de integrantes de esta división, fuesen menores que los citados en las líneas precedentes. En este caso, llama la atención que en los años anteriores a la Guerra del Asiento solo se contase con un efectivo para todo el virreinato. No obstante, se debe advertir que también fueron denominados con la expresión ingeniero director jefe, principalmente cuando debían trasladarse para suplir la ausencia de sus superiores. Bajo esta fórmula trabajaron, entre otros, Juan Bautista Mac-Evan y Manuel de Anguiano en las obras de Cartagena de Indias ${ }^{50}$.

El grado más elevado pertenecía a los ingenieros directores, encargados de liderar los proyectos, coordinar el desarrollo de las obras y nombrar a los subalternos de cada provincia. La dificultad para alcanzar este rango hizo que, en América, de los veinte directores que trabajaron para la Corona durante el siglo XVIII, apenas coincidiesen tres. De hecho, en la Nueva Granada no llegaron a coexistir, denotando lo excepcional del nombramiento y la escasez de integrantes en este escalafón. Así, según los datos obtenidos, tan solo alcanzaron el grado de ingeniero director Juan de Herrera y Sotomayor, nombrado en 1732, Lorenzo de Solís, ascendido en 1752 con el grado de brigadier, y Antonio de Arévalo, designado en $1775^{51}$. Éstos se ocuparon de comandar las obras de Cartagena de Indias, reconocido como el principal puerto neo-

48 Hoja de servicio de Juan Ximénez Donoso, Madrid, 1 de enero de 1787, Fdo. Juan Caballero, AGS, Secretaría de Guerra, Indiferente, leg. 5837, c. 2, fol. 26.

49 Hoja de servicio del Conde de Roncalli, Madrid, 7 de mayo de 1777, Fdo. Silvestre Abarca, AGS, Secretaría de Guerra, Indiferente, leg. 3793, c. 2, fol. 48.

50 Hoja de servicio de Manuel de Anguiano, Madrid, 1 de enero de 1787, Fdo. Juan Caballero, AGS, Secretaría de Guerra, Indiferente, leg. 5837, c. 1, fol. 109.

51 Hoja de servicio de Antonio de Arévalo, Madrid, 1 de enero de 1787, Fdo. Juan Caballero, AGS, Secretaría de Guerra, Indiferente, leg. 3837, c. 1, fol. 2. 
granadino ${ }^{52}$. Desde aquí, Herrera y Arévalo fueron requeridos por su experiencia para cumplir con misiones diplomáticas o para reconocer los proyectos de otras ciudades, destacando por una movilidad tan asombrosa como excepcional dentro del virreinato. Distinto fue el caso de Solís, pues, como ya se ha apuntado, pasó como director a las fortificaciones de Veracruz en 1758.

A estas actuaciones, que valieron para reordenar la profesión de ingeniero en las Indias, hay que agregar los cambios institucionales del Cuerpo, entre los que destaca la división en tres ramos efectuada en 1774. Este hecho coincidió con la década de mayor acopio de estos militares en la Nueva Granada, precisamente en el periodo comprendido entre el mandato del General Juan Martín Cermeño y de Silvestre Abarca ${ }^{53}$.

\section{MoviLIDAD DE LOS INGENIEROS SEGÚN SUS PROYECTOS Y EXPEDICIONES}

En las líneas precedentes se han apuntado algunos de los objetivos perseguidos por los ingenieros en los distintos destinos. Partiendo de tales consideraciones y analizando la documentación generada durante las misiones, se evidencia que, junto a la seguridad de las plazas, estos militares atendieron otros encargos de similar importancia, destacándose el establecimiento de un orden social que permitiese la pacificación de las tribus locales, así como la reordenación territorial y urbanística de las principales capitales neogranadinas. En relación con los sistemas defensivos, la presencia en la costa de la Nueva Granada de una serie de puertos fundamentales en la red comercial española, hacía necesaria la acumulación de suficientes ingenieros que garantizasen su protección ${ }^{54}$.

Las continuas ofensivas a las capitales de Tierra Firme por los militares enemigos durante el siglo XVIII generaron un contexto de incertidumbre política y comercial que imposibilitaba el control de la zona. De entre todas las plazas, Portobelo se instituyó como la de mayor trascendencia mercantil, pues desde allí partían los productos provenientes del Perú, convirtiéndose en objetivo prioritario de los asaltos ingleses tras la firma de los Pactos de Familia. Además, los británicos contaban con la colaboración de los indios Cunas y Mosquitos, con quienes compartían el deseo de acabar con el dominio español en el istmo ${ }^{55}$. Éstos colaboraron activamente en las batallas du-

\footnotetext{
52 Gámez Casado, 2018c: 45-53.

53 Cruz Freire, 2017.

54 Kuethe, 1979: 141-160.

55 Castillero Calvo, 1995, capítulo XIII. Sobre este tema, puede verse Gómez González,
} 2008: 143-163. 
rante la guerra de Sucesión, así como en los asedios del almirante Hosier en 1726, el de Edward Vernon en 1739 y en el bombardeo de William Kinghills en 1744, entre otros ${ }^{56}$. Con estos enfrentamientos, los ingleses pretendían interrumpir por un lado la conexión entre Portobelo y los puertos del norte del Caribe, y por otro la ruta trazada entre la ciudad panameña y Cartagena de Indias, impidiendo que los comerciantes partiesen hacía la Península Ibérica. Esta circunstancia convertía a la plaza cartagenera en blanco especial de los intentos de conquista, como prueban no solo los asedios de Pointis y de Vernon, sino también otros carentes de tal entidad.

Mismo caso ocurría con las ciudades del este de la Nueva Granada, consideradas de menor repercusión mercantil, pero de similar valor estratégico. En el extremo oriental, la eficaz defensa de Santa Marta tras las reformas de sus fortificaciones a mediados del Setecientos llevó a Maracaibo los continuos ataques de los piratas ${ }^{57}$. Allí también se refugiaban los ingleses que combatieron en Puerto Cabello, ciudad emplazada en una ensenada de aguas tranquilas e ideales para el comercio. Dicha plaza, junto al muelle de La Guaira, formaron el sector estratégico de mayor apetencia para Inglaterra, ya que del control de ambos puntos dependían las provisiones de las provincias inmediatas, caso de Trinidad, Cumaná y Margarita, y la seguridad de la Compañía Guipuzcoana ${ }^{58}$. Esta decisiva ubicación provocó en 1743 el ataque más violento contra Puerto Cabello, demostrando una falta de protección en la costa de la comandancia de Caracas y contrastando con la atención que los virreyes prestaban a la defensa de otros puertos en el virreinato.

Las continuas ofensivas descritas generaban una destrucción permanente de las fortificaciones que constituían el sistema de protección de cada una de las ciudades. Así, resulta evidente que los ingenieros militares tuvieron entre sus principales encargos no solo la reconstrucción de las murallas, fuertes y baluartes, sino también la modernización de sus diseños. Para asumir este proceso, trazaron multitud de planos que servían para explicar el proyecto, conseguir la aprobación de los gobernantes y guiar a los directores de obras. En este sentido, es paradigmática la reforma de la muralla de la Marina de Cartagena de Indias, pues las repetidas sacudidas del mar en unas cortinas degradadas por los cañonazos enemigos, obligó a modificarla en varias ocasiones. Así, los primeros planos fueron trazados por Juan de Herrera y Soto-

\footnotetext{
56 Castillero Calvo, 2016: 419-454.

57 López Rivero, 1965: 26 y ss.

58 Zapatero, 1988: 43-46.
} 
mayor en 1715, José de Figueroa incorporó nuevos cambios años más tarde y, finalmente, Antonio de Arévalo trazó el último proyecto en $1769^{59}$.

Por otro lado, la catalogación de hasta veintidós planos en archivos españoles referentes a las modificaciones del sistema defensivo del canal de Bocachica, junto a los once que se refieren a la reforma del castillo de San Felipe de Barajas, demuestran la importancia de los proyectos asumidos por los ingenieros en Cartagena, siendo ésta la capital que cuenta con más fortificaciones en la Nueva Granada. Esta condición no es óbice para considerar a otras como Portobelo, donde el plan proyectado conjuntamente por Ignacio Sala y Manuel Hernández generó varias decenas de planos conservados ${ }^{60}$.

Asimismo, al no encontrarse el sistema defensivo más seguro para Puerto Cabello, fueron muchos los ingenieros requeridos en las obras del fuerte de San Felipe, contabilizándose hasta treinta planos trazados a lo largo de todo el siglo XVIII. Éstos no solo se deben a Juan de Gayangos Lascari, pues otros ingenieros también intervinieron en la remodelación de dicho edificio en las últimas décadas de la centuria, caso de Juan Amador Courten, Esteban Aymerich o el Conde de Roncalli, así como el propio Agustín Crame, quien trazó unos bocetos de carácter general como resultado de su visita de $1778^{61}$.

Los proyectos de fortificaciones aludidos son únicamente ejemplos de la abundante actividad ingenieril producida en las tres comandancias neogranadinas durante el siglo XVIII. La importancia de estos encargos repercutía en

59 De entre todos los planos catalogados acerca de los proyectos sucesivos de reforma de la muralla del Norte, véase Plano de la Marina de la Ciudad de Cartagena de las Yndias desde el Baluartes de la Cruz, hasta el de la Santa Catalina, 1715, Archivo General de Indias, Sevilla (AGI), Mapas y Planos, MP-Panamá, 122 y Plano de la muralla real de la parte de la mar del norte de Cartagena de Yndias, 1769, Centro Geográfico del Ejército, Madrid (CGE), Mapas y Planos, J-7-2-79.

60 Varios son los planos, perfiles y elevaciones trazados por Ignacio Sala y Manuel Hernández sobre Portobelo y catalogados en los archivos españoles. Ejemplo de ellos son Plano particular de la ciudad de San Felipe de Portobelo, 1753, Archivo General Militar, Madrid (AGMM), Sección Planos, PAN-3/1 y Plano y perfil de una de dos casas-fuertes construidas con las mismas medidas sobre el alto San Fernando, 1760, CGE, Mapas y Planos, J-T4-C.4-39.

61 Se han contabilizado hasta seis planos firmados por Agustín Crame en relación a su visita a Puerto Cabello, estos son: Plano de fuerte proyectado para el Mirasor, 1778, AGMM, Sección Planos, VEN-1/10; Plano de Puerto Cabello y sus inmediaciones, 1778 AGMM, Sección Planos, VEN-5/4; Plano de Puerto Cabello y sus inmediaciones, 1778, AGMM, Sección Planos, VEN-5/5; Plano de Puerto Cabello y sus inmediaciones, 1778, AGMM, Sección Planos, VEN-5/7; Plano del castillo de San Felipe de Puerto Cabello, 1778, AGMM, Sección Planos, VEN-7/11; y Plano del castillo de San Felipe de Puerto Cabello, 1778, AGMM, VEN-7/12. 
que fuesen pocos los ingenieros que dejaron la dirección de las fortificaciones de las capitales para cumplir con otras aspiraciones fuera de ellas. Ello se justificaba en la particular estrategia de defensa española, basada en la construcción de fuertes, baterías y murallas que resistiesen los ataques navales enemigos. Por ello, debe tenerse en cuenta el elevado número de planos existentes sobre fortificaciones de la Nueva Granada, pues su alto porcentaje en relación con la producción total de los ingenieros prueba la importancia que se le otorgaba a la protección de este territorio.

Además de las tareas de fortificación, deben considerarse las distintas expediciones para la pacificación de las tribus locales. El rechazo mostrado por los pueblos indígenas al dominio español en América generó continuos enfrentamientos entre ambas partes, no siendo hasta la llegada al trono de Carlos III cuando se dispuso por las Reales Órdenes del 1 y 6 de febrero de 1760 que las incursiones fueran pacíficas ${ }^{62}$. Con la promulgación de estas normas se buscaba apaciguar la resistencia nativa, así como alcanzar la definitiva aceptación del poder español por los indios. Estos grupos se encontraban principalmente en La Guajira y en el Darién, donde destacaban los belicosos Cunas. En ambas regiones, los nativos contaron con el apoyo de los ingleses, quienes desde Jamaica enviaban expediciones que, aprovechando la coyuntura, intentaban obtener beneficios mercantiles, estratégicos y territoriales ${ }^{63}$.

No obstante, para luchar contra las circunstancias citadas, desde los primeros años del siglo XVIII los ingenieros militares compaginaron sus tareas edilicias en las capitales con misiones diplomáticas destinadas a pacificar a los indios locales. Éste fue el caso de Juan de Herrera y Sotomayor, quien en torno a 1700 sondeó algunos de los puertos más desconocidos para la gobernación española en el Darién, buscando aquéllos donde la presencia de nativos rebeldes fuese mayoritaria. Para contrarrestarlas, proyectó una serie de fortificaciones en la Nueva Calidonia, puerto utilizado por los escoceses para contrabandear con las tribus, intercambiándose ropa, comida y armas que fortalecían la resistencia local contra la Corona española ${ }^{64}$.

Sin embargo, a partir de la segunda mitad del siglo XVIII, el virrey Pedro Messía de la Cerda envió a varios ingenieros para establecer relaciones diplo-

\footnotetext{
62 Vásquez Pino, 2012: 90.

63 Feliciano Ramos, 1990: 141.

64 Plano topográfico e hidrográfico del paraje que pobló y fortificación que hizo la nación escocesa nombrado por ellos Nueva Calidonia en las costas del Darien, 1700, AGI, Mapas y Planos, MP- Panamá, 119 y Descripción geográfica e hidrográfica del paraje que poblaron y fortificaron los escoceses en la costa y provincia del Darién llamado por ellos Nueva Calidonia, 1700, AGI, Mapas y Planos, MP- Panamá, 120.
} 
máticas con los clanes. De entre ellos, Antonio de Arévalo intentó un acercamiento con los Cunas en 1761, resultando fallido ante el rechazo de éstos a cualquier representante del gobierno español ${ }^{65}$. Idéntica era su pretensión con los guajiros, obteniendo un resultado similar al fracasar su propósito de alcanzar un acuerdo de paz. Ambos casos demuestran que estos militares ejercieron como representantes del gobierno, lo que indica un reconocimiento de sus labores por parte de la Corona. Este cargo era consecuencia de la formación académica tan esmerada de los ingenieros, pues más allá de proyectar fortificaciones, podían ejercer como diplomáticos con otras fuerzas contrarias al gobierno español en la Nueva Granada.

Diferente fue el carácter de las misiones encargadas de delinear mapas que facilitasen el conocimiento del terreno, al incluir los ríos, montañas y fondeaderos en los que se refugiaban los indios. Al respecto, deben citarse las empresas que algunos como Juan Jiménez Donoso, Antonio de Narváez o Francisco de Navas afrontaron en el Darién, inspeccionando el curso del río Átrato, principal foco de asentamientos indígenas. Con esta información se facilitaba tanto la delimitación del espacio a defender, como el modelo de fortificación, siendo buena prueba de ello los proyectos que Antonio de Arévalo realizó para el río Caimán en el Darién o el trazado para la ciudad guajira de Sabana del Valle 6 .

La tercera de las actividades asumidas por los ingenieros corresponde a la supervisión, fundación y equipamiento de las ciudades. Dentro de estas labores se encontraba el diseño de otras arquitecturas que mejorasen la vida cotidiana en las distintas plazas. Entre ellas, destacó la construcción de hospitales, como el lazareto trazado por Antonio de Arévalo para Cartagena de Indias en 1764 en sustitución del antiguo, pues su cercanía al fuerte de San Felipe de Barajas vulneraba la seguridad del recinto ${ }^{67}$. También a Arévalo correspondió el diseño de las llamadas bóvedas de Santa Clara, almacén para pólvora, pertrechos y demás útiles de guerra, en ocasiones empleado para otros fines, mediante el cual reorganizó la zona norte de Cartagena, evitando la desatención y el desorden predominante hasta entonces.

Idéntico objetivo buscaban Juan de Gayangos Lascari, con la traza de un almacén para Puerto Cabello, y Manuel Hernández, quien hizo lo propio en Portobelo con el diseño de un recinto destinado a guardar los útiles de guer-

\footnotetext{
65 Zapatero, 1965: 48-81.

66 Sobre este último proyecto puede verse Gámez Casado, 2016: 373- 386.

67 Plano y perfiles del Hospital para enfermos leprosos de San Lázaro de Cartagena de Indias, 1764, AGI, Mapas y Planos, MP-Panamá, 248.
} 
ra $^{68}$. De este modo, la gobernación local aprovechaba la versatilidad de los ingenieros, ante la falta de arquitectos formados, para dotar a la ciudad de las infraestructuras necesarias. A ello se le deben sumar las intervenciones en iglesias y otros templos, documentándose las labores de Antonio de Narváez y Juan Antonio Chacón en la catedral de Santa Marta ${ }^{69}$.

No obstante, dentro del capítulo destinado a la relación existente entre la ciudad y el ingeniero, destaca la labor de este último como urbanizador de fundaciones ex novo. Para ello, era necesario un minucioso conocimiento de las regiones circundantes, existiendo en la documentación infinidad de planos, mapas y descripciones acerca de los ríos, montañas y caminos que jalonaban el virreinato. Solo así, se podía elegir el mejor emplazamiento para la creación de nuevas plazas, destinadas a fines diversos, aunque relacionados con la conquista territorial. Éste fue el caso de ciudades como Bahía Honda, fundada por Arévalo en La Guajira como consecuencia de su política de pacificación de las tribus locales. Lo mismo ocurrió con la ciudad portobeleña de San Cristóbal, fundada en 1680 como San Carlos, pero modificada por Herrera y Sotomayor en 1731 tras ejecutar un proyecto propio que definió su ordenación urbanística $^{70}$.

\section{Conclusiones}

Ciertamente, la presencia de ingenieros militares españoles en la Nueva Granada fue un aliciente dentro del proceso de transferencia cultural experimentado por la Corona durante el siglo XVIII, al trasladar a América modelos, diseños e ideas que paulatinamente acomodarían a un contexto muy distinto al europeo. Asimismo, la rigurosa formación recibida en las Academias, instituciones consecuentes de la fundación del Real Cuerpo, les convertía en un

68 Planos y perfil de un almacén de pólvora para Puerto Cabello, 1758, AGI, Mapas y Planos, MP-Venezuela, 141; y Planta y perfil de un almacén de fusiles en Puerto Cabello, 1758, AGI, Mapas y Planos, MP-Venezuela, 142.

69 Plano, vistas y perfiles de la Santa Iglesia Catedral que se está construyendo en la ciudad de Santa Marta, 1767, AGI, Mapas y Planos, MP-Panamá, 176; y Plano, perfiles y semivista de la fachada principal de la iglesia catedral que se intenta hacer en la ciudad de Santa Marta, 1778, AGI, Mapas y Planos, MP-Panamá, 256. Igualmente, Antonio de Arévalo proyectó la iglesia del nuevo hospital de San Lázaro, cuya traza incluyó en el plano general ya citado.

70 Plano del proyecto de la nueva ciudad de Portobelo que, con el nombre de San Carlos, se principió su recinto el año de 1680, y ahora de orden de SM se ha mandado continuar nombrando san Cristóbal, 1731, CGE, Mapas y Planos, J-T.4-C.4-32. 
personal garante de la introducción en las Indias de un vasto conocimiento en materias dispares. Además de dominar distintas técnicas de dibujo, estaban instruidos en otras ciencias, tales como las matemáticas, la geometría y la aritmética. Por ello, no cabe duda de que los ingenieros deben ser considerados como protagonistas no solo de la historia de las fortificaciones neogranadinas, sino también del propio pasado virreinal, pues las autoridades delegaron en ellos responsabilidades estratégicas, sociales y económicas esenciales para el buen gobierno.

Por otro lado, la división del virreinato en tres comandancias facilitaba la organización administrativa, incluyendo lo relativo a la defensa de las plazas. Esta compartimentación posibilitaba una jerarquización de las ciudades en función de su categoría política, de su actividad mercantil o de su repercusión social. Además, permitía que los ingenieros fuesen destinados para cumplir con las misiones requeridas por cada enclave, repercutiendo en cada una de las tareas realizadas por éstos. Así, se ha comprobado cómo, junto a los trabajos desempeñados en las plazas designadas, se podían encargar de otras labores en las regiones colindantes, pues eran eximidos de cualquier obligación con respecto a ciudades más alejadas. Asimismo, fijadas las residencias en las principales capitales, los traslados hacia otros puntos eran temporales, correspondiendo a encargos específicos que no requerían más de varias semanas.

Por otro lado, las distintas guerras acaecidas a mediados del siglo XVIII en el mar Caribe condicionaron el envío de ingenieros españoles a Tierra Firme. Durante la primera mitad de la centuria, la presencia de dichos militares obedecía a un porcentaje habitual en comparación a las otras realidades del continente. No obstante, los continuos ataques perpetrados por la milicia británica obligaron a la Corona a destinar hasta veinte efectivos durante la década de 1770, alcanzándose la mayor concentración de éstos en todo el siglo. A pesar de ello, como se ha analizado, la mencionada cuantía era inferior a la alcanzada en el virreinato de Nueva España, considerada como la Dirección de Ingenieros más destacada de cuantas poseyó la Corona en América.

En cuanto a la movilidad de los ingenieros españoles en la Nueva Granada, los datos presentados en los capítulos precedentes demuestran que fue escasa, siendo mayor el porcentaje de aquéllos que permanecieron fijos en una ciudad. La razón principal residía en la desatención mostrada por la Corona en puntos secundarios, concentrando los mayores esfuerzos defensivos únicamente en las capitales y denegando la presencia de militares en zonas alejadas. Es cierto que esta circunstancia varió durante la segunda mitad del siglo XVIII, cuando se reconoció la importancia de regiones como el Darién o La Guajira. No obstante, también se ha apuntado que la mayor parte de estas tareas fueron ejecutadas por ingenieros en jefe o de rango inferior, pues 
los superiores, especialmente los directores, tan solo dejaron sus destinos para supervisar obras puntuales.

De este modo, analizada la movilidad en función de la escala facultativa acordada por el Cuerpo, se manifiesta como los extraordinarios y los ordinarios despuntaron por su presencia en varias plazas. Es probable que ello fuese consecuencia del bajo costo que supondrían sus traslados para las arcas estatales, al pertenecer a este grupo militares jóvenes que no tenían que sufragar el desplazamiento de sus esposas e hijos. Caso contrario ocurría con los directores, quienes eran requeridos por un corto periodo de tiempo en varios destinos. Ciertamente, el amplio conocimiento demostrado por estos últimos los convertía en un personal capital para el avance de las políticas de protección fomentadas por la Corona en la Nueva Granada, asumiendo la supervisión de las obras y la organización de los subordinados.

En este sentido, era habitual que los ingenieros más experimentados examinasen los proyectos destinados a otras plazas desde su punto de destino. Ello generó numerosos debates entre los gobernadores y los militares, pues, en multitud de ocasiones, estos últimos exigían reconocer el territorio sobre el que se iba a construir la fortificación. Esta necesidad se basaba en la intención constante del ingeniero por facilitar los trabajos, ya que no solo permitiría la adaptación del diseño a una determinada orografía, sino que también analizaría las distancias entre las canteras más cercanas para extraer la piedra.

Así, las gráficas y los porcentajes resultantes del estudio ahora presentado demuestran como existían casos excepcionales de movilidad dentro de los ingenieros españoles. En este sentido, se podrían citar los casos de Agustín Crame y Antonio de Arévalo, quienes por diferentes razones ya apuntadas se desplazaron a más de tres ciudades neogranadinas. Sin embargo, esta circunstancia no era la habitual, pues un porcentaje menor apenas se trasladó a otras ciudades distintas a la de su primer destino, mientras que la mayoría restante destacó por su falta de desplazamientos. Ello nos permite concluir que la movilidad de los ingenieros militares en la Nueva Granada fue mínima, a pesar de la existencia de algunos casos que exceptúan tal afirmación.

Por otra parte, se han señalado los diversos objetivos perseguidos en sus expediciones, pues en ocasiones, lejos de ocuparse de las fortificaciones de una plaza, se encargaron de otras tareas. Así, el estatismo predominante entre los ingenieros españoles no condicionó el papel que obtuvieron en la administración neogranadina. El conocimiento directo de las ciudades les permitió aconsejar a los gobernantes en materia defensiva, política e incluso económica. Además, los exigentes planes de estudios superados en las Academias de Matemáticas los convirtió en un personal especializado en disciplinas cientí- 
ficas, poseedores de una esmerada instrucción militar y beneficiarios de un elevado estatus público. Todo ello contribuyó a considerarlos como reputados profesionales, pues, sin duda, llegaron a formar parte de la élite social neogranadina.

Sobre el papel del ingeniero en la administración americana se debe hacer hincapié en futuros estudios. Asimismo, importante será reconocer en próximas publicaciones la función de los ingenieros militares en el control del territorio americano, en la culturización de los pueblos nativos y en la ocupación de cargos gubernamentales. Estas peculiaridades de tan afamada profesión, inexistentes en otros campos del arte y la cultura, deben considerarse en paralelo al estudio de las fortificaciones que diseñaron, pues solo así se valorará la importancia de estos militares en la organización cultural, política y artística del Nuevo Mundo.

\section{Bibliografía}

AA.VV., Los ingenieros militares en España: siglo XVIII. Repertorio biográfico e inventario de su labor cientifica y espacial, Barcelona, Editorial Universidad, 1983.

Angulo Íñiguez, Diego, Bautista Antonelli: las fortificaciones americanas del siglo XVI, Madrid, Real Academia de la Historia, 1952.

Arcos Martínez, Nelly, "Territorio y fortificación del Caribe: Agustín Crame, visitador de plazas, 1777-1779", Biblio, 21 (Barcelona, 2016): 1-38.

Borrero Londoño, Ricardo, "De Pointis y la representación textual de la expedición a Cartagena en 1697: tipología discursiva, ambigüedad y pragmatismo trascendental”, Fronteras de la Historia, XIV/2 (Bogotá, 2009): 368-390.

Brown, Kendall, "Guerra, impuestos y reformas financieras: las colonias españolas e inglesas del siglo XVIII", Histórica, II (Lima, 2015): 117-150.

Calderón Quijano, José Antonio, "Noticia de los ingenieros militares en Nueva España en los siglos XVII y XVIII", Anuario de Estudios Americanos, VI (Sevilla, 1950): 1-72.

Calderón Quijano, José Antonio, Historia de las fortificaciones en Nueva España, Sevilla, CSIC, 1984.

Calderón Quijano, José Antonio, Las fortificaciones españolas en América y Filipinas, Madrid, Mapfre, 1996.

Cámara, Alicia y Revuelta, Bernardo (eds.), Libros, caminos y días. El viaje del ingeniero, Madrid, Fundación Juanelo Turriano, 2016. 
Capel, Horacio, Sánchez, Joan Eugeni y Moncada, Omar, De Palas a Minerva. La formación científica y la estructura institucional de los ingenieros militares en el siglo XVIII, Barcelona, Editorial Universitaria, 1988.

Castillero Calvo, Alfredo, Conquista, evangelización y resistencia, Panamá, Novo Art, 1995.

Castillero Calvo, Alfredo, Portobelo y el San Lorenzo del Chagres. Perspectivas imperiales. Siglos XVI-XIX, Panamá, Novo Art, 2016, tomo II.

Cruz Freire, Pedro, "El ingeniero militar Ignacio Sala, gobernador y comandante general de Cartagena de Indias. Noticias de su pase a Indias y de su labor en las defensas de la ciudad", Laboratorio de Arte, 25 (Sevilla, 2013): 469-481.

Cruz Freire, Pedro, Silvestre Abarca. Un ingeniero militar al servicio de la monarquía hispana, Sevilla, Athenaica, 2017.

Cruz Freire, Pedro y López Hernández, Ignacio J. (coords.), Ingeniería e ingenieros en la América hispana. Siglos XVIII y XIX, Sevilla, Editorial Universidad de Sevilla, 2017.

De la Torre Echávarri, José Ignacio, "Juan Bautista Antonelli: ingeniero militar y alojador de ejército", Alicia Cámara y Bernardo Revuelta (eds.), Ingenieros del Renacimiento, Madrid, Fundación Juanelo Turriano, 2014: 113-155.

Feliciano Ramos, Héctor, El contrabando inglés en el Caribe y el Golfo de México. 1748-1778, Sevilla, Diputación Provincial, 1990.

Galland Seguela, Martine, "Los ingenieros militares españoles en el siglo XVIII", Alicia Cámara (ed.), Los ingenieros militares de la monarquía hispánica en los siglos XVII y XVIII, Madrid, Fundación Juanelo Turriano, 2005: 205-229.

Gámez Casado, Manuel, "La pacificación de La Guajira por el ingeniero Antonio de Arévalo. Sobre el proyecto de defensa de Sabana del Valle", Laboratorio de Arte, 28 (Sevilla, 2016): 373-386.

Gámez Casado, Manuel, "Ingenieros militares y arquitectura defensiva en Cartagena de Indias tras el ataque del barón de Pointis", Rafael López Guzmán (ed.), De Sur a Sur. Intercambios artísticos y relaciones culturales, Granada, Editorial Universitaria, 2017: 179-184.

Gámez Casado, Manuel, "Buscando al enemigo inglés. Expediciones de guardacostas españoles al golfo del Darién, 1767-1768", Anuario Estudios Americanos, 75 (Sevilla, 2018a): 211-236.

Gámez Casado, Manuel, "De ingeniero voluntario a ingeniero extraordinario. El acceso al Cuerpo de don Antonio de Narváez y la Torre", AA.VV., La formación artística: creadores-historiadores-espectadores, Santander, Editorial Universitaria, 2018b: 237-246. 
Gámez Casado, Manuel, "Cartagena de Indias: la bahía más codiciada”, AA.VV., Mares Fortificados. Protección y defensa de las rutas de globalización en el siglo XVIII, Sevilla, Editorial Universitaria, 2018c: 45-53.

Gámez Casado, Manuel, "Ingenieros militares y obras públicas. Algunos ejemplos de Nueva Granada en el siglo XVIII", Ars Longa, 27 (Valencia, 2018d): 125-138.

Gasparini, Graziano, "Las fortificaciones del puerto de La Guaira durante el periodo colonial", AA.VV., Memoria del tercer congreso venezolano de historia, Caracas, Academia de la Historia, 1979: 11-98.

Gómez González, Juan Sebastián, "Las tensiones de una frontera ístmica: alianzas, rebeliones y comercio ilícito en el Darién. Siglo XVIII", Historia y sociedad, XV (Medellín, 2008): 143-163.

Gómez Molleda, María Dolores, "El contrabando inglés en América", Hispania, Revista española de historia, 39 (Madrid, 1950): 336-369.

González, Asdrubal, "La fortificación de Puerto Cabello: una empresa económico-militar", AA.VV., Memoria del tercer congreso venezolano de historia, Caracas, Academia de la Historia, 1979: 127-137.

González Tascón, Ignacio, Ingeniería española en Ultramar. (Siglos XVI-XIX), Madrid, CEHOPU, 1992.

Guarda, Gabriel, "Influencia militar en las ciudades del Reino de Chile", Boletín de la Academia Chilena de Historia, 75 (Santiago, 1966): 5-55.

Gutiérrez, Ramón, Fortificaciones en Iberoamérica, Madrid, Iberdrola, 2015.

Herrera Ángel, Marta, "Las divisiones político-administrativas del Virreinato de la Nueva Granada a finales del periodo colonial", Historia Crítica, 22 (Bogotá, 2001): 76-104.

Justiniano Carranza, Ángel, El almirante Vernon en las aguas de Nueva Granada. 1739-1741, Buenos Aires, 1874.

Kuethe, Allan, "The pacification campaign on the Rio Hacha frontier, 1772-1779", The Hispanic American Historical Review, 50/3 (Duke, 1970): 467-481.

Kuethe, Allan, "Reforma militar y control politico en la Nueva Granada", AA.VV., Memoria del tercer congreso venezolano de historia, Caracas, Academia de la Historia, 1979: 141-160.

Kuethe, Allan y Kenneth, Andrien, The spanish Atlantic World in the eighteenth century. War and the Bourbon Reforms. 1713-1796, Nueva York, Cambridge Press, 2014.

Langebaek, Carl Henrik, "La descripción de la provincia del Darién en 1763 por Antonio de Arévalo", Boletín de Arqueología, IV (Bogotá, 1989): 41-50.

Laorden Ramos, Carlos, Obra civil en Ultramar del Real Cuerpo de Ingenieros, Madrid, Ministerio de Defensa, 2008, 2 vols. 
López Guzmán, Rafael y Cabrera Cruz, Alfonso, "La visión del virrey Sebastián de Eslava del asedio de Cartagena de Indias en 1741. El funcionamiento de las fortificaciones", Pedro Cruz Freire e Ignacio José López Hernández (coords.), Ingeniería e ingenieros en la América Hispana. Siglos XVIII y XIX, Sevilla, Editorial Universidad, 2017: 49-75.

López Hernández, Ignacio J., "La defensa de Santiago de Cuba al ataque de Vernon de 1741: principios de fortificación para la guerra en el Caribe", Anuario de Estudios Americanos, 76 (Sevilla, 2019): 177-207.

López Rivero, Raúl Tomás, Fortificaciones de Maracaibo. Siglos XVII y XVIII, Maracaibo, Editorial Municipal, 1965.

Lozano, Álvaro, "La toma de Portobelo por el almirante Vernon”, Historia 16, 209 (Madrid, 1993): 39-47.

Luengo Gutiérrez, Pedro, "Ingenieros militares y construcción en Cuba", Rafael López Guzmán (ed.), Patrimonio histórico: difusión e imbricación americana, Granada, UNIA, 2013: 261-266.

Luengo Gutiérrez, Pedro, "Movilidad de los ingenieros militares en Cuba a finales del siglo XVIII", Quiroga, 6 (Granada, 2014): 36-47.

Luengo Gutiérrez, Pedro, "Military engineering in eighteenth-century Havana and Manila: the experience of the seven years war", War in history, 24/1 (Glasgow, 2017a): 4-27.

Luengo Gutiérrez, Pedro, "La fortificación de Puerto España (Trinidad y Tobago) en el siglo XVIII", Rafael López Guzmán (ed.), Actas Congreso De Sur a Sur. Intercambios artísticos y relaciones culturales, Granada, Editorial Universitaria, 2017b: 215-222.

Marco Dorta, Enrique, Cartagena de Indias. Puerto y plaza fuerte, Bogotá, Fondo Cultural, 1988.

Mazorra Acosta, Henry, "Los ingenieros militares y la arquitectura del edificio-teatro en la Cuba colonial", Atrio, XV- XVI (Sevilla, 2009): 37-46.

Moncada Maya, José Omar, "Ciencia en Acción. Ingenieros militares en Nueva España en el siglo XVIII”, Revista de Historia Militar, XXXVI/72 (Madrid, 1992): $11-47$.

Moncada Maya, José Omar, El ingeniero Miguel Constanzó. Un militar ilustrado en la Nueva España del siglo XVIII, México, UNAM, 1994.

Moncada Maya, José Omar, "Influencia militar en el desarrollo urbano. Los ingenieros militares en la América colonial”, Minius, XIX (Vigo, 2011): 79-101.

Moncada Maya, José Omar, Miguel Constanzó y la Alta California: crónica de sus viajes (1768-1770), México, UNAM, 2012. 
Morales, Alfredo J., "Los ingenieros de Carlos III", AA.VV., El Greco en su IV Centenario: patrimonio hispánico y diálogo intercultural. XX Congreso CEHA, Toledo, CEHA, 2014.

Muñoz Corbalán, Juan Miguel, "La profesión del ingeniero en la Ilustración”, Alicia Cámara Muñoz (ed.), Ingeniería de la Ilustración, Madrid, Fundación Juanelo Turriano, 2015: 11-34.

Navarro García, Luís, Hispanoamérica en el siglo XVIII, Sevilla, Editorial Universitaria, 1975.

Ojeda Pérez, Robert, "Producción, comercio y contrabando del vino en el virreinato de la Nueva Granada en el periodo colonial", Memorias, 7 (Barranquilla, 2007): 93- 113.

Oliveros de Castro, María Teresa, "La Guajira y las ordenaciones de don Antonio de Arévalo", Revista de Historia Militar, XXII (Madrid, 1967): 79-111.

Pocock, Tom, The battle for empire: the very first World War, 1756-1763, Londres, Michael O'Mara Books, 2002.

Polo Acuña, José, "Antonio de Arévalo y la frontera de la península de La Guajira. 1770-1776", Taller de Historia, 1 (Cartagena de Indias, 2001): 196-229.

Porras Troconis, Gabriel, "La toma de Cartagena por Pointis", América española, XIV (Madrid, 1942): 81-90.

Porto de González, Judith, "Ataque de Vernon a Cartagena", Boletín de Historia y Antigüedades, 83/794 (Madrid, 1996): 679-694.

Robles, Gregorio y Tau, Víctor, América a fines del siglo XVII: noticias de los lugares de contrabando, Valladolid, Editorial Universitaria, 1980.

Rodríguez Hernández, Nelson Eduardo, "Cartografía de la frontera bárbara. Las representaciones del Darién a propósito del conflicto entre el virreinato de Nueva Granada y los Cunas", Anuario de Historia regional y de las fronteras, XIX (Bogotá, 2014): 59-78.

Serrano Álvarez, José Manuel, "El éxito de la escasez. La defensa de Cartagena de Indias en 1741", Vegueta, XIV (Las Palmas, 2006): 359-383.

Vásquez Pino, Daniel, "Políticas borbónicas en la frontera. El caso del Darién. 17601810", Revista de Historia 2.0/II (Bucaramanga, 2012): 89-103.

Zapatero, Juan Manuel, "Expediciones españolas al Darién. La del ingeniero don Antonio de Arévalo en 1761", Revista de Historia Militar, 19 (Madrid, 1965): $50-60$.

Zapatero, Juan Manuel, "La Escuela de Fortificación Hispanoamericana", AA.VV., XXXVI Congreso Internacional de Americanistas, Sevilla, ECESA, 1966, vol. IV: 61-69. 
Zapatero, Juan Manuel, La fortificación abaluartada en América, San Juan de Puerto Rico, Instituto de Cultura Puertorriqueña, 1978.

Zapatero, Juan Manuel, "El ingeniero militar de Cartagena de Indias don Antonio de Arévalo, 1742-1800", Anuario de Estudios Americanos, 38 (Madrid, 1981): 441-465.

Zapatero, Juan Manuel, Historia del Castillo de San Lorenzo el Real de Chagres, Madrid, CEHOPU, 1985a.

Zapatero, Juan Manuel, Dos ejemplos de fortificaciones españolas en la exposición de puertos y fortificaciones en América y Filipinas, Madrid, Comisión de Estudios Históricos, $1985 \mathrm{~b}$.

Zapatero, Juan Manuel, Las fortalezas de Puerto Cabello, Madrid, CEHOPU, 1988.

Fecha de recepción: 1 de agosto de 2017.

Fecha de envío de las modificaciones: 19 de octubre de 2017.

Fecha de aceptación: 11 de diciembre de 2017.

\section{Military engineers in New Granada during the eighteenth century. Mobility, projects and expeditions}

The principle aim of this article is to analyse the degree of mobility among Spanish engineers among the principal cities of the Viceroyalty of New Granada during the eighteenth century. The results obtained allow the significance of those movements between regions to be assessed, as they relate to the duties the Spanish professionals were sent to carry out. Additionally, the situation in New Granada will be compared with other Caribbean territories.

Key words: Engineer; Caribbean; Mobility; War; American History. 